National Marine

Fisheries Service

NOAA
Fishery Bulletin

कs established in $1881 \approx$
Spencer F. Baird

First U.S. Commissione of Fisheries and founder of Fishery Bulletin
Abstract-Understanding fisheryindependent survey selectivity is fundamental to relating relative abundance indices to total population size. The selectivity of a survey in an assessment model represents a combination of gear selectivity and availability of fish to the gear. Concerns have been raised about possible bias in sampling of the bottom trawl survey (BTS) of the NOAA Northeast Fisheries Science Center (NEFSC) caused by the challenges associated with towing in roughbottom habitat. These difficulties may affect the availability of some fish, such as large ( $\geq 100 \mathrm{~cm}$ in total length [TL]) Atlantic cod (Gadus morhua). To evaluate the potential presence of BTS habitat-related bias, we compared catches of Atlantic cod and white hake (Urophycis tenuis) from BTS sampling in the Gulf of Maine with catches from the NEFSC bottom longline survey, which focuses on rough-bottom habitats in the same region. Differences between survey catches were apparent for large white hake ( $\geq 90 \mathrm{~cm}$ TL), supporting the premise of availability differences between surveys for white hake and the assumption of dome-shaped selectivity for the BTS. In contrast, results for Atlantic cod did not support the hypothesis of habitat-related bias in sampling of the BTS, supporting continued use of asymptotic selectivity for Atlantic cod in the BTS.

Manuscript submitted 16 November 2020. Manuscript accepted 22 September 2021. Fish. Bull. 119:231-242 (2021). Online publication date: 3 November 2021. doi: $10.7755 /$ FB.119.4.3

The views and opinions expressed or implied in this article are those of the author (or authors) and do not necessarily reflect the position of the National Marine Fisheries Service, NOAA.

\title{
Comparison of a bottom longline survey and a bottom trawl survey for 2 groundfish species in the Gulf of Maine to evaluate habitat-related availability of large fish
}

\author{
W. David McElroy (contact author) ${ }^{1}$ \\ Jessica Blaylock ${ }^{2}$ \\ Gary R. Shepherd (retired) ${ }^{3}$
}

Christopher M. Legault ${ }^{3}$

Paul C. Nitschke ${ }^{3}$

Katherine A. Sosebee ${ }^{3}$

Email address for contact author: dave.mcelroy@noaa.gov

${ }^{1}$ Cooperative Research Branch Northeast Fisheries Science Center National Marine Fisheries Service, NOAA 166 Water Street

Woods Hole, Massachusetts 02543

${ }^{2}$ Fisheries Monitoring Operations Branch Northeast Fisheries Science Center National Marine Fisheries Service, NOAA 166 Water Street

Woods Hole, Massachusetts 02543

Fishery-independent scientific surveys can be used to produce relative abundance indices for fish stocks, as well as demographic and biological data, that are free of biases associated with commercial catches, and as such they are an integral part of many stock assessments (Hilborn and Walters, 1992). In the northeastern United States, the NOAA Northeast Fisheries Science Center (NEFSC) uses data from its bottom trawl survey (BTS) to inform assessments of finfish and marine invertebrate stocks. The BTS was designed to sample the northwestern Atlantic Ocean between Cape Hatteras, North Carolina, and Nova Scotia, Canada (Grosslein ${ }^{1}$; Azarovitz, 1981) and follows a stratified random design with stratification determined by depth and geographic region (Stauffer, 2004). Stock assessments by the NEFSC

\footnotetext{
${ }^{1}$ Grosslein, M. D. 1969. Groundfish survey methods. Bur. Commer. Fish., Woods Hole Lab. Ref. Doc. 69-02, 34 p. [Available from website.]
}

${ }^{3}$ Population Dynamics Branch Northeast Fisheries Science Center National Marine Fisheries Service, NOAA 166 Water Street Woods Hole, Massachusetts 02543 assume that the BTS data can be used to produce representative estimates of the characteristics of each stock, including trends in abundance, distribution across habitats, sex structure, and size and age compositions.

The catch of a given species from a fishing event depends on a combination of 2 main factors: fish availability and gear selectivity (Crone et al. ${ }^{2}$; Maunder et al., 2014). Availability refers to the probability that the fish are in proximity to the gear and are vulnerable to possible capture. As such, availability is primarily determined by the spatial distribution of different sizes of fish relative to the distribution of survey sampling. Gear selectivity (hereafter referred to as selectivity) refers to the probability that a fish of a given length

\footnotetext{
${ }^{2}$ Crone, P., M. Maunder, J. Valero, J. McDaniel, and B. Semmens (eds.). 2013. Selectivity: theory, estimation, and application in fishery stock assessment models. Workshop Ser. Rep. 1, 9 p. Cent. Adv. Popul. Assess. Methodol., La Jolla, CA.[Available from website.]
} 
will be captured if the gear encounters it. Several factors can affect selectivity, including fishing gear characteristics and fish behavior (Crone et al. ${ }^{2}$ ). Selectivity influences the relationship between the size composition of the fish caught in the survey and the size composition of the population (Crone et al. ${ }^{2}$; Maunder et al., 2014). Therefore, understanding a fishery-independent survey's selectivity, along with its underlying assumptions, is fundamental to the interpretation of the resulting index of relative abundance and of its ability to track the population trends and cohorts. This selectivity can be modeled as curves describing the probability of capture at length and may have 4 general shapes: increasing, asymptotic, dome-shaped, and saddle-shaped (Sampson and Scott, 2012). The most common selectivity curve used in stock assessments is flat-topped selectivity, a form of asymptotic selectivity in which the proportion of a demographic group that is vulnerable to the gear increases over the lifespan of the group until all members are fully vulnerable (Cadrin et al., 2016).

The Atlantic cod (Gadus morhua), hereafter primarily referred to as cod, has historically been the focal species of the New England groundfish fishery. In the Gulf of Maine (GOM), commercial landings, mostly caught with trawl and gill nets, exceeded 10,000 metric tons (t) in the early 1990s. However, this level of exploitation has not been sustainable because population abundance has been in a downward trajectory since the 1980s (NEFSC, 2013a). According to the most recent assessment $\left(\mathrm{NEFSC}^{3}\right)$, the GOM cod stock is overfished and experiencing overfishing with spawning stock biomass at $6-9 \%$ of the biomass target. In response to the stock condition, annual quotas have been reduced to $<1000 \mathrm{t}$ in recent years $\left(\mathrm{GARFO}^{4}\right)$.

One of the consequences of continued overfishing has been the truncation of the size and age compositions of the GOM cod stock. Data from the NEFSC BTS, which has involved sampling in the area since 1963 (Grosslein ${ }^{1}$; Azarovitz, 1981), indicate that large cod $(\geq 100 \mathrm{~cm}$ in total length [TL]) were consistently present from the onset of the survey until the mid-1980s, when they represented on average about $8 \%$ of the annual catches (Fig. 1) (data from the NEFSC 2019 GOM Atlantic cod stock assessment [NEFSC ${ }^{3}$ ], available from website). Since then, their encounter rate has gradually declined and they have become rare in BTS catches $(<1 \%$ on average) over the past 10 years. The commercial landings indicate a consistent but low presence of cod $\geq 100 \mathrm{~cm}$ TL, typically composing $1-2 \%$ of the annual landings since the early 1980 s (Fig. 1). In addition to a reduction in abundance of fish at this size range, there has been a truncation of the age structure of cod caught in the BTS and in the commercial fishery beyond age 8 , despite a potential maximum age greater than 20 years $\left(\mathrm{NEFSC}^{3}\right)$.

\footnotetext{
${ }^{3}$ NEFSC (Northeast Fisheries Science Center). In preparation. Operational assessment of 14 Northeast groundfish stocks, updated through 2018. Northeast Fish. Sci. Cent. Ref. Doc. [Available from website.]

${ }^{4}$ GARFO (Greater Atlantic Regional Fisheries Office). 2019. Northeast multispecies (groundfish) fishing year 2019 commercial regulations. 18 July 2019. [Available from website.]
}

The white hake (Urophycis tenuis) is another important groundfish species in the GOM with recent annual commercial landings around $2000 \mathrm{t}$, predominantly caught with trawl gear. The stock was considered overexploited in 2008 (NEFSC, 2008) and is currently overfished (with biomass at less than half of the biomass at maximum sustainable yield), although fishing mortality has been reduced to a level below the threshold for overfishing $\left(\mathrm{NEFSC}^{3}\right)$. The commercial fishery routinely encounters white hake older than 9 years (NEFSC, 2013b; NEFSC ${ }^{3}$ ), indicating that mature individuals are present in the population. However, large white hake ( $\geq 90 \mathrm{~cm} \mathrm{TL}$ ) have been uncommon in the size composition of the BTS since the beginning of the time series in 1963 (Fig. 1) (data from the NEFSC 2019 white hake stock assessment [NEFSC ${ }^{3}$, available from website).

Consequently, the recent stock assessment applied a dome-shaped selectivity pattern at age for indices of abundance and biomass derived from data collected during the spring and fall BTS (NEFSC, 2013b, 2017; NEFSC ${ }^{3}$ ); this selectivity pattern assumes that the largest or oldest members of a demographic group are not fully vulnerable to survey gear because of gear avoidance (Sampson and Scott, 2012; Cadrin et al., 2016). In contrast, white hake $\geq 90 \mathrm{~cm}$ TL have composed a significant portion of the commercial landings since the mid-1990s, with at least $6 \%$ of landings exceeding $90 \mathrm{~cm}$ TL in most years since 2000 (Fig. 1). The difference in commercial versus survey selectivity is presumably a result of commercial fleets targeting fishing locations and of different tow speeds and durations (K. Sosebee, personal commun.).

The truncated size (and age) distribution of adult cod as well as a decline in weight at age for fish at ages 3 and above have been a concern for fishery managers for some time (NEFSC, 2008, 2017). Previous discussions and analyses considered several possible reasons for the truncation, such as the presence of fixed gears (e.g., lobster gear) in inshore areas that would make potential cod habitat unavailable for sampling during the BTS or decreased selectivity of large fish in the fishery; however, no supporting evidence was found (NEFSC, 2013a). An alternative explanation may be linked to the history of the GOM cod stock. A significant decline in abundance, as experienced by this stock, can affect the spatial distribution of a stock. Range contraction and density-dependent habitat selection can occur in depleted stocks (Holt, 1987; Lawton, 1993), and both processes have been documented for cod (Swain and Wade, 1993; Hutchings and Reynolds, 2004; Tamdrari et al., 2010). Other factors, such as prey distribution and climate change, may also influence the spatial distribution of groundfish in general and of cod in particular (Nye et al., 2009; Ames and Lichter, 2013; Orio et al., 2019). Given the combined circumstances of overfishing and changes in environmental conditions in the ecosystem of the GOM $\left(\mathrm{NEFSC}^{5}\right)$, it is possible that the spatial

\footnotetext{
${ }^{5}$ NEFSC (Northeast Fisheries Science Center). 2019. State of the ecosystem 2019: New England, 31 p. Report to the New England Fisheries Management Council. [Available from website.]
} 

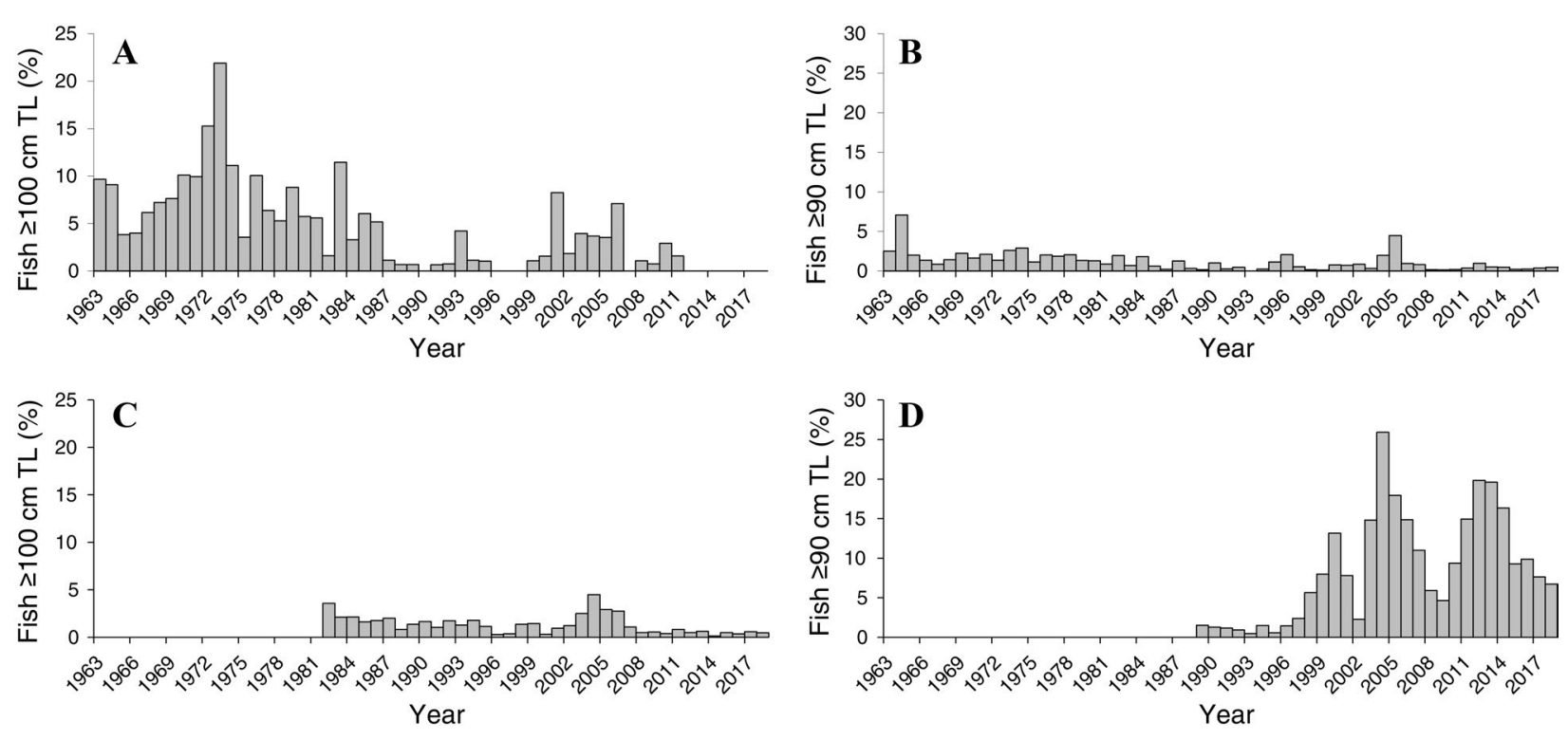

Figure 1

Percentage of large Atlantic cod (Gadus morhua) ( $\geq 100 \mathrm{~cm}$ in total length [TL]) (left panels) and white hake (Urophycis tenuis) $(\geq 90 \mathrm{~cm}$ TL) (right panels) captured in the Gulf of Maine (A and $\mathbf{B}$ ) in the NOAA Northeast Fisheries Science Center bottom trawl survey (BTS) during 1963-2018 and (C and D) in the commercial fishery, based on commercial landings (CL) data used in the stock assessments, during 1982-2018 for Atlantic cod and during 1989-2018 for white hake. Because of changes over time in size regulations of the fishery for the Gulf of Maine Atlantic cod stock, the percentages represented are relative to the total number of individuals $\geq 50 \mathrm{~cm}$ TL. The percentages of white hake are relative to fish of all sizes because there is no size limit for this stock.

distribution of cod has changed over the last 50 years and that some portion of the stock (e.g., large cod, $\geq 100 \mathrm{~cm} \mathrm{TL}$ ) has shifted to habitat that cannot consistently be sampled as part of the BTS.

Although the BTS research vessel has an otter trawl outfitted with large roller (rockhopper) gear $40.6 \mathrm{~cm}$ in diameter (Politis et al. ${ }^{6}$ ) to accommodate the variety of bottom habitat types in the sampling area, towing of the trawl gear in highly structured habitat is limited on the basis of the likelihood of the gear getting stuck on the rugged bottom. Consequently, organisms that inhabit rough-bottom habitats are less available to BTS sampling. There is a concern, particularly among industry stakeholders, that large cod may have a reduced distribution and are limited to hard-bottom habitats that are difficult to sample with mobile trawl gear. If large adult cod have moved to hard-bottom locations, it would result in a change in their vulnerability to the survey gear and could explain the truncation of the size distribution evident in the BTS data. Although adult cod are known to inhabit areas with substrates of sand, gravel, or mud, they do have an affinity for rocky bottoms, and their distribution among habitats can vary among seasons and sizes (Scott, 1982; Fahay

\footnotetext{
${ }^{6}$ Politis, P. J., J. K. Galbraith, P. Kostovick, and R. W. Brown. 2014. Northeast Fisheries Science Center bottom trawl survey protocols for the NOAA ship Henry B. Bigelow. Northeast Fish. Sci. Cent. Ref. Doc. 14-06, 138 p. [Available from website.]
}

et al., 1999). If the spatial distribution of large cod in the GOM has changed, it could indicate that BTS selectivity for cod may be more dome-shaped, like the selectivity for white hake, rather than flat-topped, which is the type of selectivity used in the stock assessment for cod (NEFSC, 2013a, 2017). The consequences of incorrectly specifying a flat-topped selectivity curve when a dome-shaped curve is warranted would be an underestimation of stock abundance and biomass.

In 2014, the NEFSC started a bottom longline survey (LLS) to address concerns about the presence of fish species in rough-bottom habitat in the GOM that may experience low encounter rates with the trawl survey. The LLS was designed following a stratified random design similar to that of the BTS, but the LLS survey area was further stratified by bottom type, with classification of smooth and rough bottom (McElroy et al., 2019). Because of the concentrated effort of the LLS in rough-bottom habitats, data from the LLS provide a perspective on availability of groundfish in the GOM complementary to the BTS.

With respect to cod, the LLS stratification design offers an opportunity to evaluate the presence of large cod in the rough-bottom areas of the GOM. If data from the LLS indicate that large cod are more prevalent in the roughbottom habitats than across the BTS sampling area, it would provide support for considering dome-shaped selectivity for the BTS in the GOM cod stock assessment. On the other hand, if large cod are not caught at a higher rate 
in the LLS compared with the rate of capture in the BTS, it would be unclear whether it is due to low selectivity in the longline gear or simply due to the absence (i.e., low availability) of these fish. To address this question, we used white hake as a control for the selectivity of the longline gear. Atlantic cod and white hake, the latter of which has an accepted dome-shaped selectivity for the BTS, are generally similar gadoids in size (both can exceed $100 \mathrm{~cm}$ TL), prey types, and prey size (Scharf et al., 2000). Therefore, we would expect both species to have comparable probability of capture with the LLS gear. In other words, if large white hake ( $\geq 90 \mathrm{~cm} \mathrm{TL}$ ) are caught in the LLS, we would expect large cod to be caught as well, if these fish are present. Conversely, if large white hake are caught in the LLS but large cod are not, we would deduce that large cod are not present in the area. This approach offers an avenue to examine whether data from the LLS supports the presence of large cod in the rough-bottom habitat of the GOM.

The objectives of this study were to evaluate the relative size distributions of Atlantic cod and white hake in the LLS and BTS and to test the hypothesis that availability by size is different between the predominantly smooth-bottom habitats sampled with bottom trawl gear and the roughbottom habitats sampled with longline gear. Specifically, we will focus on the upper end of the size distributions of the LLS and BTS catches to explore whether they differ for each species. Depending on the results, as explained previously, our findings may indicate the need for reconsideration of the selectivity curve used for the BTS in the GOM Atlantic cod stock assessment. In addition, results of our analysis can also validate the current BTS selectivity assumed for the white hake assessment.

\section{Materials and methods}

The NEFSC has been conducting the BTS in the fall since 1963 and in the spring since 1968 (Azarovitz, 1981). This survey follows a stratified random sampling design, with stratification by depth and region, for selection of sampling stations in federal waters on the continental shelf from Cape Hatteras to the Scotian Shelf (Stauffer, 2004; Politis et al. ${ }^{6}$ ). Stations are randomly selected within each stratum prior to each survey cruise, with the number of stations selected per stratum being proportional to the area of the stratum, typically with a minimum of 3 stations per stratum (Politis et al. ${ }^{6}$ ). Although several factors are considered before a tow begins (e.g., presence of shipwrecks or fixed gear and strength of bottom current), bottom type does not specifically affect the determination of a tow location. Since 2009, the NEFSC has used the NOAA Ship Henry B. Bigelow as the primary research vessel for the BTS. The NOAA Ship Pisces was used in the fall of 2017; however, because the 2 vessels are the same size and class it is assumed that changes in vessel did not affect selectivity. Each vessel used a 4-seam, 3-bridle bottom trawl with a rockhopper sweep (Politis et al. ${ }^{6}$ ) that can be used in a variety of habitat types. At each station, data on the abundance, biomass, and size distribution of fish were collected for each species. Fish TL was measured (to the nearest $0.5 \mathrm{~cm}$ ) by using digital fish measuring boards.

The LLS, which is an industry-based survey implemented by the NEFSC (McElroy et al., 2019), has occurred concurrently with the spring and fall BTS since 2014. The further stratification of sampling by bottom type for the LLS is based on rugosity. Bottom type was defined as either smooth or rough, with rough-bottom habitats having a terrain ruggedness index value (Riley et al., 1999) greater than the 70th percentile within each stratum (McElroy et al., 2019). With the participation of 2 commercial fishing vessels, the sampling of the LLS occurs between $42.0^{\circ} \mathrm{N}$ and $43.5^{\circ} \mathrm{N}$, an area that encompasses all or portions of 6 BTS strata (Fig. 2). Sampling density is higher in the LLS than in the BTS, and stations are more heavily allocated to rough-bottom substrata in the LLS (Politis et al. ${ }^{6}$; McElroy et al., 2019). In the current allocation of stations sampled in the LLS, $84 \%$ of stations are in rough-bottom strata, and the sampling in the BTS when stratified post hoc by using the LLS strata includes $20-35 \%$ of stations in the rough-bottom strata per year (Suppl. Table).

Tub-trawl longlines are used for the LLS with gear similar to those used commercially for groundfish species, such as cod and white hake, in the region. The longline gear is deployed with 1000 12/0 semicircle E-Z baiter hooks ${ }^{7}$ (O. Mustad and Son AS, Gjøvik, Norway) on 38-cm gangions that are baited with squid on a $1.85-\mathrm{km}$ (1-nmi) mainline and soaked for $2 \mathrm{~h}$ across the slack tide (McElroy et al., 2019). The hook size and soak time were chosen to be relatively comparable with some commercial groundfish operations, and the soak time was standardized across the slack tide to get a portion of both sides of a tide. The mainline length was chosen to be consistent with the mean tow distance of the BTS. At each station, data on the abundance, biomass, and size distribution of fish were collected for each species. Fish TL was measured (to the nearest $0.5 \mathrm{~cm}$ ) by using digital fish measuring boards.

Length frequencies of cod and white hake caught in the LLS and BTS were generated by using TL by season for the period 2014-2018. For the BTS, data from all stations meeting gear and operational acceptance criteria (Politis et al. $^{6}$ ) were included from stock assessment strata sets for each species: offshore strata $26-30$ and 36-40 for the GOM cod stock (NEFSC, 2013a) and offshore strata 21-30 and 36-40 for the white hake stock (NEFSC, 2013b) (Fig. 2). Use of stock assessment strata for the BTS reflects the intent of the analysis to relate the findings about availability of cod and white hake in the roughbottom habitat of the GOM based on data from the LLS to the respective stocks as a whole, rather than simply comparing BTS and LLS results in the overlapping area. For the LLS, data from all stations that met gear and operational acceptance criteria (McElroy et al., 2019) were

\footnotetext{
${ }^{7}$ Mention of trade names or commercial companies is for identification purposes only and does not imply endorsement by the National Marine Fisheries Service, NOAA.
} 


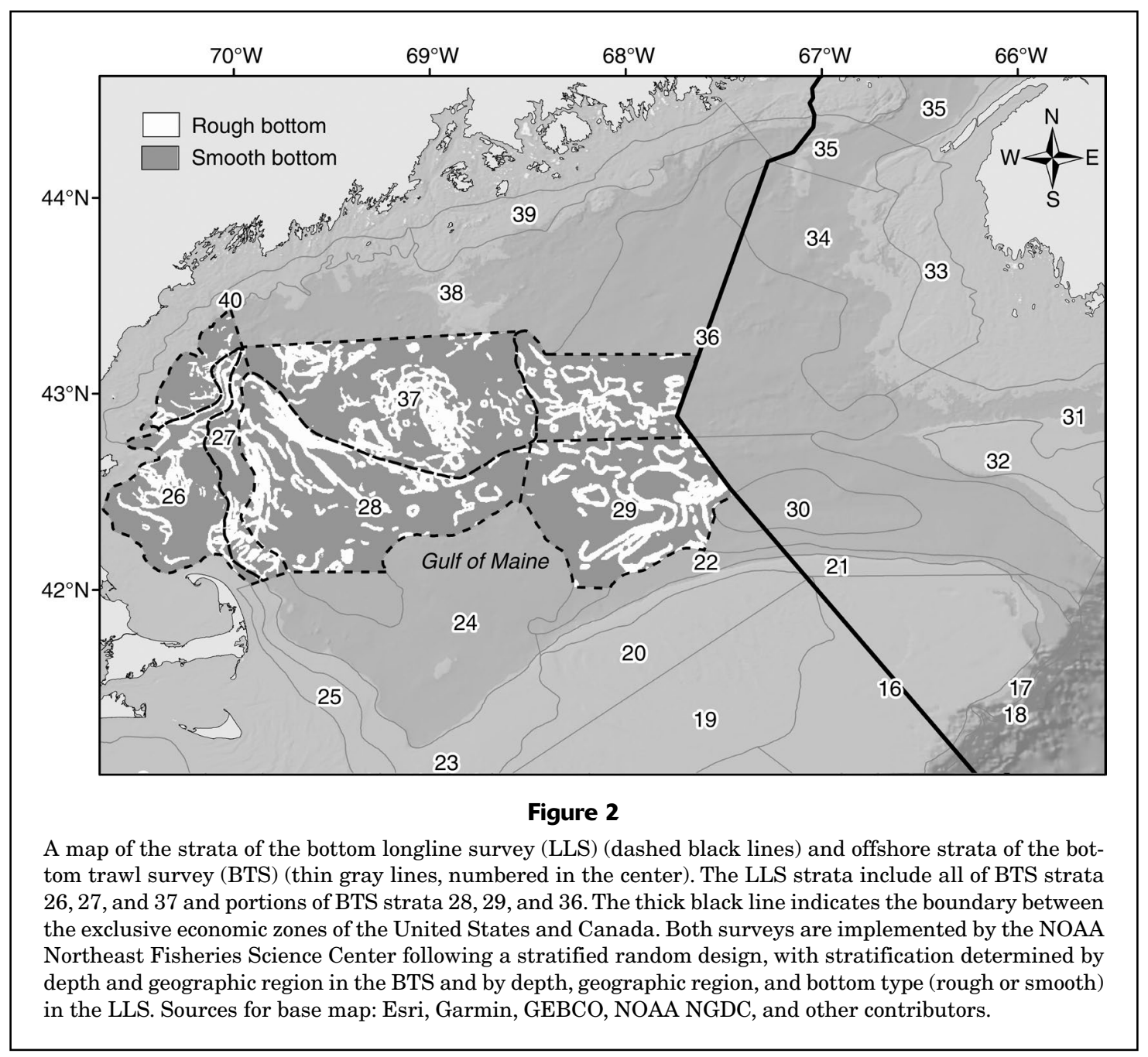

included from LLS strata that were located on rough bottom where towing is difficult. Stations of the LLS on smooth bottom were omitted because of concerns about low catchability due to poor bait retention on soft bottom (McElroy et al., 2019).

For each species, year, and season, we first calculated estimates of aggregate (i.e., all lengths combined) stratified mean abundance indices (for the BTS, see Cochran, 1977; for the LLS, see McElroy et al., 2019). Second, we used the length frequencies from the raw data to derive estimates of stratified mean abundance indices at length (i.e., mean numbers at each length). The indices of abundance at length were then standardized to produce estimates of the proportion of numbers at length as a representation of length distributions. The Bhattacharyya coefficient (BC) (Bhattacharyya, 1943) was calculated as a measure of overlap between the lengthfrequency distributions of the 2 surveys, for each species and season. This coefficient provides a robust measure of relative similarity in distribution ranging from 0.0 , indicating no overlap, to 1.0 , indicating identical distributions (Winner et al., 2018).

\section{Results}

Sampling coverage of the study area was comparable between the 2 gear types. The LLS data sets used in analysis included data from 33-38 stations in each season in each year, 349 stations in total (Table 1). In 2017 and 2018 , modifications to the method of station allocation for the LLS resulted in increased sampling in rough-bottom habitat (McElroy et al., 2019). The BTS data sets used in analysis included at least 50 stations in the spring and fall for GOM Atlantic cod and white hake (Table 1) during 2014-2017, for a total of 550 stations sampled. Because of operational difficulties, fewer stations were sampled in the BTS in 2018, resulting in a reduced sample size.

On average, the species of interest were adequately represented in the catches of both the LLS and BTS. During the LLS, catches of cod occurred at $73 \%$ of stations in the spring, and at $70 \%$ of stations in the fall, yielding lengths of 1603 individuals in the spring and of 1330 individuals in the fall (Table 1). For white hake, the rate of encounter in the LLS averaged $50 \%$ in the spring and $74 \%$ in the fall, producing lengths of 882 individuals in the spring 


\section{Table 1}

The number of stations, number of stations with catch, and number of sampled Atlantic cod (Gadus morhua) and white hake (Urophycis tenuis) for which lengths were recorded in the Gulf of Maine as part of the NOAA Northeast Fisheries Science Center bottom longline survey (LLS) and bottom trawl survey (BTS) during 2014-2018, by season and year. Data were selected from strata with rough bottom for the LLS and from strata used in the stock assessments for these species for the BTS (for strata used in the assessments, see NEFSC, 2013a, 2013b).

\begin{tabular}{|c|c|c|c|c|c|c|c|c|}
\hline \multirow[b]{2}{*}{ Species } & \multirow[b]{2}{*}{ Season } & \multirow[b]{2}{*}{ Year } & \multicolumn{3}{|c|}{ LLS } & \multicolumn{3}{|c|}{ BTS } \\
\hline & & & $\begin{array}{c}\text { No. of } \\
\text { stations } \\
\text { sampled }\end{array}$ & $\begin{array}{c}\text { No. of } \\
\text { stations } \\
\text { with catch }\end{array}$ & $\begin{array}{l}\text { No. of } \\
\text { fish with } \\
\text { lengths } \\
\text { recorded }\end{array}$ & $\begin{array}{c}\text { No. of } \\
\text { stations } \\
\text { sampled }\end{array}$ & $\begin{array}{c}\text { No. of } \\
\text { stations } \\
\text { with catch }\end{array}$ & $\begin{array}{l}\text { No. of } \\
\text { fish with } \\
\text { lengths } \\
\text { recorded }\end{array}$ \\
\hline \multirow[t]{12}{*}{ Atlantic cod } & \multirow[t]{6}{*}{ Spring } & 2014 & 33 & 26 & 285 & 61 & 19 & 112 \\
\hline & & 2015 & 33 & 26 & 346 & 65 & 29 & 696 \\
\hline & & 2016 & 33 & 22 & 401 & 66 & 32 & 299 \\
\hline & & 2017 & 38 & 28 & 251 & 52 & 27 & 143 \\
\hline & & 2018 & 38 & 25 & 320 & 30 & 11 & 48 \\
\hline & & Total & & & 1603 & & & 1298 \\
\hline & \multirow[t]{6}{*}{ Fall } & 2014 & 33 & 23 & 184 & 58 & 18 & 215 \\
\hline & & 2015 & 33 & 26 & 333 & 66 & 20 & 55 \\
\hline & & 2016 & 33 & 28 & 252 & 65 & 16 & 199 \\
\hline & & 2017 & 37 & 23 & 245 & 50 & 20 & 121 \\
\hline & & 2018 & 38 & 20 & 316 & 37 & 8 & 134 \\
\hline & & Total & & & 1330 & & & 724 \\
\hline \multirow[t]{12}{*}{ White hake } & \multirow[t]{6}{*}{ Spring } & 2014 & 33 & 11 & 48 & 82 & 51 & 465 \\
\hline & & 2015 & 33 & 14 & 129 & 91 & 61 & 599 \\
\hline & & 2016 & 33 & 15 & 160 & 91 & 75 & 718 \\
\hline & & 2017 & 38 & 24 & 329 & 77 & 48 & 583 \\
\hline & & 2018 & 38 & 24 & 216 & 47 & 36 & 379 \\
\hline & & Total & & & 882 & & & 2744 \\
\hline & \multirow[t]{6}{*}{ Fall } & 2014 & 33 & 22 & 267 & 82 & 68 & 578 \\
\hline & & 2015 & 33 & 24 & 264 & 89 & 78 & 1175 \\
\hline & & 2016 & 33 & 27 & 302 & 91 & 76 & 1022 \\
\hline & & 2017 & 37 & 27 & 337 & 68 & 56 & 709 \\
\hline & & 2018 & 38 & 28 & 556 & 60 & 47 & 453 \\
\hline & & Total & & & 1726 & & & 3937 \\
\hline
\end{tabular}

and of 1726 individuals in the fall. Atlantic cod were present in sampling of the BTS at $43 \%$ and $30 \%$ of stations in the spring and fall, respectively (Table 1). There was a difference between seasons in sample size in the BTS for cod, with lengths of 1298 individuals measured in the spring and of 724 individuals measured in the fall. White hake were more prevalent than cod in catches of the BTS, with white hake caught at $70 \%$ of the stations sampled in the spring and at $83 \%$ of the stations sampled in the fall. Lengths were collected from 2744 and 3937 white hake sampled during the BTS in the spring and fall, respectively. The number of lengths recorded during the BTS were low for both species in 2018 compared with in 20142017, especially for cod (Table 1).

Overall, the size distribution of cod captured in the LLS was similar to that in the BTS (Table 2, Fig. 3). Mean length of cod in the BTS was $50.7 \mathrm{~cm}$ TL (standard deviation [SD] 15.2; range: $15-93 \mathrm{~cm}$ TL) in the spring and $53.4 \mathrm{~cm}$ TL (SD 23.0; range: 13-93 cm TL) in the fall; whereas, the mean length of cod in the LLS was $50.0 \mathrm{~cm}$ TL (SD 10.5; range: $24-91 \mathrm{~cm}$ TL) in the spring and $58.9 \mathrm{~cm}$ TL (SD 16.4; range: $26-103 \mathrm{~cm} \mathrm{TL}$ ) in the fall. Length distributions for cod from both surveys were very comparable, particularly for cod over $40 \mathrm{~cm}$ TL (Fig. 3). The distribution for cod caught in the BTS in spring was characterized as bimodal, split around the length of $25 \mathrm{~cm}$ TL, with fish below that size not fully represented. The distribution for cod caught in the BTS in fall was also bimodal, split around the length of $35 \mathrm{~cm}$ TL, with a large contribution from fish $<35 \mathrm{~cm}$ TL. The size distribution for cod caught in the LLS in both seasons combined was unimodal with limited representation of fish $<40 \mathrm{~cm}$ TL.

Although there were annual variations among years for both surveys (Table 2, Suppl. Figs. 1 and 2), distributions of cod length in the spring generally had high overlap from 40 to $70 \mathrm{~cm} \mathrm{TL}$, and the overlap of distributions in the fall was similar but with slightly higher proportions of fish with lengths of 40-65 cm TL in the LLS. The proportion of $\operatorname{cod} \geq 70 \mathrm{~cm}$ TL had high similarity between the surveys in the fall, with the exception of a few fish in the LLS that were $\geq 95 \mathrm{~cm}$ TL. The distributions of fish caught in the BTS and LLS largely overlapped in spring with occasional 


\section{Table 2}

Percentage of the stratified mean abundance indices by size group, season, and year, for the Atlantic cod (Gadus morhua) and white hake (Urophycis tenuis) sampled in the Gulf of Maine in 2014-2018 during the NOAA Northeast Fisheries Science Center bottom longline survey (LLS) and bottom trawl survey (BTS). Data were selected from strata with rough bottom for the LLS and from strata used in the stock assessments for these species for the BTS (for strata used in the assessments, see NEFSC, 2013a, 2013b). $\mathrm{TL}=$ total length.

\begin{tabular}{|c|c|c|c|c|c|c|c|c|c|c|}
\hline \multirow[b]{2}{*}{ Species } & \multirow[b]{2}{*}{ Season } & \multirow[b]{2}{*}{ Year } & \multicolumn{4}{|c|}{ LLS } & \multicolumn{4}{|c|}{ BTS } \\
\hline & & & $\begin{array}{c}<80 \mathrm{~cm} \\
\mathrm{TL}\end{array}$ & $\begin{array}{c}80-89 \mathrm{~cm} \\
\text { TL }\end{array}$ & $\begin{array}{c}90-99 \mathrm{~cm} \\
\text { TL }\end{array}$ & $\begin{array}{c}\geq 100 \mathrm{~cm} \\
\mathrm{TL}\end{array}$ & $\begin{array}{c}<80 \mathrm{~cm} \\
\mathrm{TL}\end{array}$ & $\begin{array}{c}80-89 \mathrm{~cm} \\
\text { TL }\end{array}$ & $\begin{array}{c}90-99 \mathrm{~cm} \\
\text { TL }\end{array}$ & $\begin{array}{c}\geq 100 \mathrm{~cm} \\
\mathrm{TL}\end{array}$ \\
\hline \multirow[t]{10}{*}{ Atlantic cod } & \multirow[t]{5}{*}{ Spring } & 2014 & 99.8 & 0.2 & 0.0 & 0.0 & 95.8 & 1.7 & 2.5 & 0.0 \\
\hline & & 2015 & 100.0 & 0.0 & 0.0 & 0.0 & 99.3 & 0.7 & 0.0 & 0.0 \\
\hline & & 2016 & 99.7 & 0.3 & 0.0 & 0.0 & 98.5 & 1.5 & 0.0 & 0.0 \\
\hline & & 2017 & 98.9 & 1.1 & 0.0 & 0.0 & 91.6 & 7.0 & 1.4 & 0.0 \\
\hline & & 2018 & 97.9 & 1.8 & 0.3 & 0.0 & 91.4 & 7.3 & 1.3 & 0.0 \\
\hline & \multirow{5}{*}{ Fall } & 2014 & 97.9 & 1.5 & 0.6 & 0.0 & 97.5 & 2.5 & 0.0 & 0.0 \\
\hline & & 2015 & 92.5 & 6.3 & 0.8 & 0.4 & 83.4 & 15.3 & 1.3 & 0.0 \\
\hline & & 2016 & 94.4 & 5.6 & 0.0 & 0.0 & 93.3 & 5.3 & 1.4 & 0.0 \\
\hline & & 2017 & 96.7 & 2.3 & 1.0 & 0.0 & 90.1 & 8.6 & 1.3 & 0.0 \\
\hline & & 2018 & 86.7 & 10.7 & 2.3 & 0.3 & 97.6 & 2.4 & 0.0 & 0.0 \\
\hline \multirow[t]{10}{*}{ White hake } & \multirow[t]{5}{*}{ Spring } & 2014 & 87.2 & 6.4 & 6.5 & 0.0 & 97.2 & 1.9 & 0.4 & 0.5 \\
\hline & & 2015 & 96.4 & 2.4 & 1.2 & 0.0 & 99.4 & 0.4 & 0.2 & 0.0 \\
\hline & & 2016 & 98.7 & 0.0 & 0.6 & 0.6 & 99.4 & 0.4 & 0.1 & 0.0 \\
\hline & & 2017 & 98.7 & 1.3 & 0.0 & 0.0 & 98.2 & 1.2 & 0.5 & 0.2 \\
\hline & & 2018 & 94.1 & 4.4 & 0.9 & 0.6 & 98.4 & 1.5 & 0.0 & 0.1 \\
\hline & \multirow[t]{5}{*}{ Fall } & 2014 & 85.8 & 8.2 & 4.0 & 2.0 & 97.8 & 2.0 & 0.0 & 0.2 \\
\hline & & 2015 & 95.1 & 2.7 & 1.2 & 1.0 & 99.1 & 0.5 & 0.1 & 0.2 \\
\hline & & 2016 & 96.4 & 1.7 & 0.7 & 1.2 & 99.4 & 0.2 & 0.3 & 0.0 \\
\hline & & 2017 & 70.3 & 11.3 & 9.2 & 9.2 & 99.1 & 0.8 & 0.0 & 0.1 \\
\hline & & 2018 & 93.3 & 4.7 & 1.1 & 0.9 & 96.8 & 0.6 & 2.3 & 0.2 \\
\hline
\end{tabular}

higher proportions of $\operatorname{cod} \geq 70 \mathrm{~cm}$ TL in the catches of the BTS. The biggest differences between the surveys were observed in catches of cod with sizes of $15-38 \mathrm{~cm}$ TL. Atlantic cod $<35 \mathrm{~cm}$ TL were regularly represented in BTS catches but were very limited in LLS catches. This difference was particularly evident in the fall, when cod at sizes of $25-38 \mathrm{~cm}$ TL were common in catches of the BTS (Fig. 3). Cod $\geq 80 \mathrm{~cm}$ TL were uncommon ( $<10 \%$ of the sampled fish; Table 2, Fig. 3) in both surveys (except for the LLS in fall 2018 and for the BTS in fall 2015) but were more frequent in the fall than in the spring for both surveys. Cod $\geq 90 \mathrm{~cm}$ TL were rare ( $<3 \%$ of the sampled fish) in most surveys and occurred more often in the fall. Only 2 $\operatorname{cod} \geq 100 \mathrm{~cm}$ TL were captured in either survey during the 5 years of data examined.

The BC, used for the comparisons of annual length distributions of Atlantic cod (Table 3) between the BTS and LLS, indicates variable but high overlap $(\mathrm{BC}=0.77-0.91)$ in the spring in all years except $2018(\mathrm{BC}=0.50)$. The $\mathrm{BC}$ indicates that overlap in distributions of the 2 surveys was generally less in the fall than in the spring but still relatively high in most years $(\mathrm{BC}=0.62-0.87)$ except, again, in 2018 ( $\mathrm{BC}=0.55)$. The BCs for surveys in 2016 are the most consistent across the 2 seasons $(0.90$ and 0.87 for spring and fall, respectively) and among the highest observed. The BCs for distributions combined across the period
2014-2018 indicate that overlap was high in both spring $(\mathrm{BC}=0.96)$ and fall $(\mathrm{BC}=0.89)$. The distributions for combined years were more complete than the distributions for individual years because the former were based on data from a larger sample than that for each individual year.

For white hake, length distributions aggregated across years were dissimilar between the LLS and BTS (Table 2, Fig. 3). White hake in the spring LLS were most commonly 40-75 cm TL (Fig. 3), and in the fall LLS the peak in the length distribution was typically $55-80 \mathrm{~cm}$ TL. In contrast, the peak abundance in the BTS was observed for fish with lengths around $32 \mathrm{~cm}$ TL in the spring, with a couple of peaks in the catches at sizes around 45 and $55 \mathrm{~cm}$ TL (Fig. 3). In catches of white hake in the fall BTS, the most prevalent sizes were around $35-50 \mathrm{~cm}$, with secondary peaks of abundance for fish at 20-30 cm TL and 60-65 cm TL (Fig. 3). Recent recruits, at sizes around $10 \mathrm{~cm} \mathrm{TL}$, occurred in the fall BTS, and white hake $<40 \mathrm{~cm}$ TL were rarely observed in LLS catches. White hake $\geq 80 \mathrm{~cm}$ TL were regularly observed at a low frequency in the spring LLS, but they were common in the catches of the fall LLS (Table 2, Suppl. Figs. 1 and 2). In contrast, white hake $\geq 80 \mathrm{~cm}$ TL, and particularly those $\geq 90 \mathrm{~cm}$ TL, were infrequent in the BTS across both seasons relative to the LLS.

White hake $\geq 90 \mathrm{~cm}$ TL composed $2-18 \%$ of the fish sampled in the LLS among years in the fall, and although 

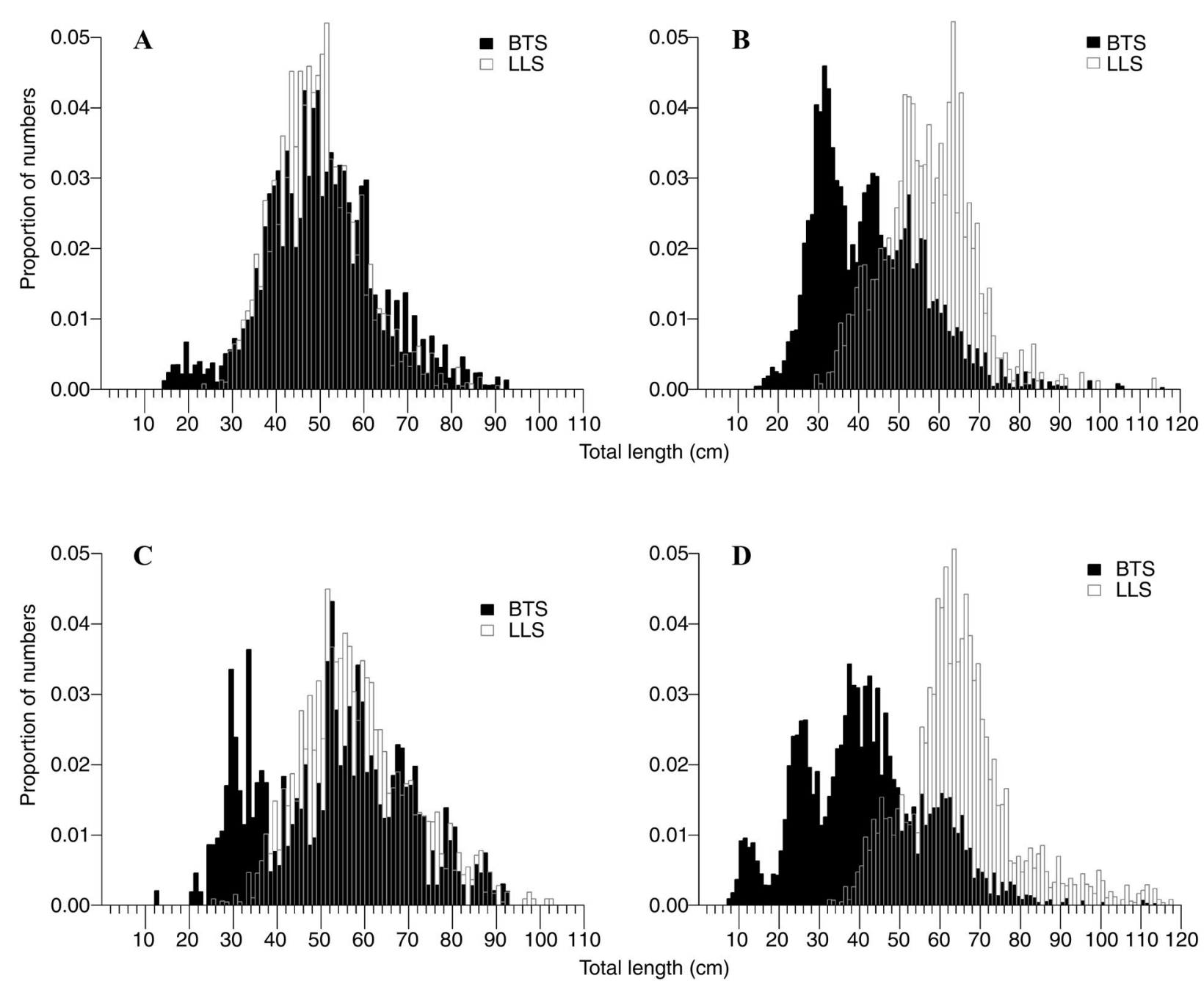

Figure 3

Length-frequency distributions of Atlantic cod (Gadus morhua) (left panels) and white hake (Urophycis tenuis) (right panels) captured in the Gulf of Maine in the NOAA Northeast Fisheries Science Center bottom trawl survey (BTS, black bars) and bottom longline survey (LLS, open bars) during (A and B) the spring and (C and D) the fall for the years 2014-2018 combined. Proportions at length were derived from indices of stratified mean abundance at length for each survey.

such white hake were present in the spring they were less common (0-7\% of the sampled fish; Table 2). White hake $\geq 100 \mathrm{~cm}$ TL were rarely captured in the spring LLS, and they were caught in low numbers (1-2\% of the sampled fish) in the fall, with the exception of some high catches in fall 2017 (9.2\% of the sampled fish; Table 2). The interannual variation of the LLS catch was more evident in the fall than in the spring, with higher catches of white hake $\geq 80 \mathrm{~cm}$ TL in 2014 (Suppl. Figs. 1B and 2B) and particularly in 2017 (Suppl. Figs. $1 \mathrm{H}$ and $2 \mathrm{H}$ ). The catch of white hake $\geq 80 \mathrm{~cm}$ TL in the BTS was limited in both seasons (averaging $1.5 \%$ of the catch in the spring and $1.6 \%$ of the catch in the fall), and fish $\geq 90 \mathrm{~cm}$ TL were rare in all seasons and years examined (Table 2, Suppl. Figs. 1 and 2).

The BC for the comparison of the BTS and LLS annual length distributions of white hake (Table 3) indicates lower overlap than was observed for cod. The BCs for white hake in spring surveys $(\mathrm{BC}=0.53-0.84)$ indicate that overlap in distributions was usually higher and more variable than that for the fall surveys $(\mathrm{BC}=0.50-0.67)$. The finding of greater variation in spring is consistent with the prevalence of white hake at more stations in the fall surveys than in the spring surveys (Table 1). The BC for the distributions combined across 2014-2018 is 0.77 for the spring surveys and only 0.65 for the fall surveys. The distributions for combined years of white hake catches were based on data from a larger sample size, filled in gaps, and decreased the differences by providing a more complete distribution than that for individual years, as was found with cod. However, the differences in distributions between the LLS and BTS were still greater for white hake than for cod. 


\section{Table 3}

Bhattacharyya coefficients (BCs) representing the degree of overlap in length distributions between the NOAA Northeast Fisheries Science Center bottom longline survey (LLS) and bottom trawl survey (BTS) for Atlantic cod (Gadus morhua) and white hake (Urophycis tenuis) sampled in the Gulf of Maine during 2014-2018 by season and year and for all years combined. Data were selected from strata with rough bottom for the LLS and from strata used in the stock assessments for these species for the BTS (for strata used in the assessments, see NEFSC, 2013a, $2013 \mathrm{~b}$ ). The BC may range from 0.00 (no overlap) to 1.00 (identical distributions).

\begin{tabular}{cccccc}
\hline & \multicolumn{2}{c}{ Atlantic cod } & & \multicolumn{2}{c}{ White hake } \\
\cline { 2 - 3 } \cline { 5 - 6 } Year & Spring & Fall & & Spring & Fall \\
\hline 2014 & 0.86 & 0.62 & & 0.53 & 0.58 \\
2015 & 0.91 & 0.75 & & 0.64 & 0.58 \\
2016 & 0.90 & 0.87 & & 0.73 & 0.67 \\
2017 & 0.77 & 0.83 & & 0.84 & 0.60 \\
2018 & 0.50 & 0.55 & & 0.63 & 0.50 \\
$2014-2018$ & 0.96 & 0.89 & & 0.77 & 0.65 \\
& & & & & \\
\hline
\end{tabular}

\section{Discussion}

The intent of this study was to evaluate the presence of large cod ( $\geq 100 \mathrm{~cm}$ TL) in the rough-bottom habitat of the GOM, as indicated by a comparison of catches of cod and white hake in the LLS and BTS conducted by the NEFSC in 2014-2018. Possible aggregation of large cod in roughbottom habitat due to presumed density-dependent range contraction could warrant reconsideration of the flattopped BTS gear selectivity currently used in the GOM cod stock assessment. Using white hake as a control, we evaluated whether the LLS and BTS data support use of a dome-shaped selectivity curve for cod in the BTS by comparing length distributions of the 2 species in each survey. Our results indicate that large cod were not more prevalent in the rough-bottom habitat sampled for the LLS than in the BTS sampling area; therefore, no evidence was found to support a dome-shaped selectivity pattern for cod in the BTS. On the other hand, our approach provided a unique opportunity for validation of the selectivity curve used for white hake. Large white hake ( $\geq 90 \mathrm{~cm}$ TL) were sparse in the BTS but present in the LLS, supporting the continued use of a dome-shaped selectivity for the BTS in the assessment for this species.

Patterns of the size distributions for the 2 gadoid species in this study are distinct between the LLS and BTS, which sample different compositions of habitats. The largest divergence in the distributions for both species occurred at small sizes ( $<35 \mathrm{~cm}$ TL), which were present in trawl catches but poorly represented in longline catches. These differences were expected given the contrasting capture mechanisms of each gear. In particular, hook and bait size, as well as mouth gape, swimming ability, and other behaviors, limit the longline selectivity for small fish, and trawls capture most fish that cannot outswim or pass through the net (Engås et al., 1996; Millar and Fryer, 1999). The efficiency of trawl gear at catching small fish increases when a lined codend is used, and the codend of the trawl net used in the BTS is lined. Cod at the upper end of the size range had similar distributions between the 2 surveys, with few large cod observed in catches with either gear. In contrast, large white hake were more abundant in the LLS than in the BTS. This pattern was relatively consistent among years despite some interannual and seasonal variation. Both gear types could have additional selectivity characteristics that contribute to the size patterns observed. However, the presence of large white hake in the LLS, which is concentrated on rough-bottom habitats, confirms that this survey is capable of catching large gadoids that are not selected by trawl gear in the areas sampled for the BTS. Therefore, given the comparable low catches of large cod in both surveys, our results indicate that BTS gear selectivity or ineffective sampling in rough-bottom habitat are not likely the cause of the absence of large cod in the BTS in recent years.

Commercial landings data support the observation of the absence of large cod in BTS catches in the GOM over a 40-year time frame. Big cod were infrequent throughout the period in both the BTS and commercial landings data sets, and when the occurrence of big fish increased, the length frequencies were still comparable between BTS catches and landings. Although the proportion of large white hake in commercial landings has varied over the past 20 years, these fish nevertheless represented a much greater proportion of the annual commercial landings than of the BTS catches in the same period. The size of fish in commercial landings for both species could be influenced by changes in market demand, fishing costs, and regulatory changes. The general expectation is that the market demand for large cod is always high for this quintessential New England seafood. Regulatory rules and low quotas could have been disincentives for cod landings in recent years and have contributed to the paucity of large cod in the commercial landings; however, these market and regulatory factors would not account for the lack of large cod in the BTS time series. In contrast, catches of large white hake have been consistently low across the BTS time series, and their proportional occurrence in the commercial landings is very high. These differences in the occurrence of large white hake have provided some of the justification for the application of a dome-shaped selectivity to the BTS time series in the assessment for white hake (NEFSC, 2013b). Although neither gear type provides complete selectivity across all fish lengths, data from the LLS provide complementary and independent validation that habitat-related availability to the BTS is likely for large white hake.

The size distribution of white hake in the LLS may reflect preference for rough-bottom habitat, particularly for large individuals, and fine-scale differences in station locations relative to rough-bottom habitat. Studies characterizing the habitat of white hake have been limited, but 
results from most of the studies indicate a preference for mud, fine-grained sand, or soft bottom (Scott, 1982; Chang et al., 1999). However, these studies relied upon fisheryindependent trawl data. Ames (2012) looked at historical seasonal movements based on interviews with fishermen and described fishing grounds not only as mostly mud bottom but also as around the ledges, rises, and banks of the northern GOM. Habitat and distribution of white hake changes with life stage (Macdonald et al., 1984; Chang et al., 1999), possibly contributing to some of the observed differences in catch composition for white hake between gears. Differences in survey catches could also be driven by behavioral factors that influence availability of the large white hake to different survey gears or by an interaction between behavior, habitat, and the response to fishing gear presence. The use of baited hooks may attract large white hake that avoid trawls behaviorally or have a habitat preference for structure.

Another possibility is that small-scale habitat variation (e.g., a few boulders or a wreck in a muddy area) may facilitate trawl gear avoidance. In a study in the Gulf of St. Lawrence, white hake were captured in channel bottoms, but the highest rate of capture was on deepwater slopes (Nozères et al. ${ }^{8}$ ). This preference for slope habitat is consistent with what was observed in the LLS, which has a bottom-type stratification derived from depth data and includes many of the sloped edges of the ledges, banks, and other structured habitats in the GOM (McElroy et al., 2019). The actual bottom type can vary greatly because the LLS classification is broad within the 2 categories of rough and smooth. The results of our study indicate at least some presence proximal to structured or slope habitats in the deeper waters of the GOM for large white hake, a habitat preference that may influence their availability to the BTS.

Habitat preference of Atlantic cod may have less influence on their availability to longline gear compared with their availability to bottom trawl gear. Cod are known for their preference for sand, gravel, rocks, ledges, slopes, and wrecks (Scott, 1982; Fahay et al., 1999; Wieland et al., 2009). However, they are also captured on other bottom types, such as mud (Macdonald et al., 1984; Wieland et al., 2009). Scott (1982) found higher concentrations of cod on sand and gravel bottoms on the Scotian Shelf but reported there was not a high preference. In a study in which multiple gear types were used, Wieland et al. (2009) found that cod prefer rough-bottom habitat, with some variation by season and gear type potentially influenced by seasonal movements. The authors also found no relationship between bottom type and cod size but cautioned that the study could not explore other factors, such as current strength or prey distribution, that could affect cod distribution. The results of the analysis presented here between the BTS and LLS

\footnotetext{
${ }^{8}$ Nozères, C., J. Gauthier, H. Bourdages, and Y. Lambert. 2015. Review of white hake (Urophycis tenuis) in the northern Gulf of St. Lawrence in support of a recovery potential assessment. DFO Can. Sci. Advis. Sec. Res. Doc. 2015/076, 56 p. [Available from website.]
}

indicate that there was no difference in the size composition for the upper end of the size distribution. Cod appear to lack a size-related habitat preference sufficient enough to limit their availability to the BTS or to limit the survey's ability to capture the full size range of the individuals present. It remains possible that size-related habitat preference is a function of population density and patterns observed now reflect the current low abundance. It seems reasonable that under conditions of reduced abundance, cod would be expected to concentrate in their preferred habitats (e.g., rocky habitat), but this notion was not supported by the catches of the LLS.

The LLS is an example of successful cooperative research that can benefit assessments and management. Although the LLS time series is short compared with that of the BTS at this time, it will be long enough in the coming years to be evaluated within a stock assessment model. Analysis of data from the LLS may result in additional indices of abundance for a few of the common fish species in the region. The emphasis on more structured habitat will particularly benefit species strongly associated with those habitats, including a number of data-poor species and those considered species of concern by the National Marine Fisheries Service, such as cusk (Brosme brosme) and thorny skate (Amblyraja radiata), which are both well represented in LLS catches. This fixed-gear survey represents a supplemental source of biological and demographic information that can be examined in conjunction with data from the BTS to gain a deeper understanding of the status of fish communities in the GOM and to advance research and management. Greater diversity of comparable surveys in which different gear types are used also provides data for a broader suite of species, further benefiting ecosystem-based management approaches.

\section{Conclusions}

The choice of selectivity for a fishery-independent survey is critical to a stock assessment because it can influence model outputs and subsequent management decisions. The results of the analysis in this study provide a unique exploration of selectivity patterns for 2 groundfish species through a comparison of catches from 2 overlapping surveys with different gear types and sampling stratifications. Our results indicate that the size selectivity for white hake differs between the 2 surveys, with large white hake readily observed in the LLS but not well represented in BTS catches. These fish may not be available to the BTS because of habitat or other factors, such as gear avoidance. Our findings validate the continued use of a dome-shaped selectivity for the BTS in the white hake stock assessment. In contrast, results indicate that catches were similar between the 2 surveys for cod in the upper end of the size distribution. A lack of large cod in the LLS, which focuses on sampling rough-bottom habitat, indicates that a similar absence of large cod in BTS catches is not due to habitatrelated availability. Therefore, our findings do not support the hypothesis of habitat-related bias in the catches of cod 
in the BTS. It remains to be determined if other factors could influence the gear selectivity or availability of large cod; however, the results of analysis in this study support the continued use of the asymptotic (flat-topped) selectivity for the BTS in the GOM cod stock assessment.

\section{Acknowledgments}

We thank captains P. Lynch (F/V Mary Elizabeth) and E. Hesse (F/V Tenacious II) and their crews for contributions to the LLS. We thank the NEFSC Cooperative Research Branch staff, particularly C. Alexander, B. Gervelis, G. Gianesin, and D. St. Amand, for their support of the LLS. Special thanks to L. O'Brien, M. Martin, and P. Rago for contributions to the design of the LLS. We are grateful to staff of the NEFSC Ecosystems Surveys Branch for tireless efforts on the BTS. Thanks to A. Wood and P. Politis for comments on an earlier draft.

\section{Literature cited}

Ames, E. P.

2012. White hake (Urophycis tenuis) in the Gulf of Maine: population structure insights from the 1920s. Fish. Res. 114:56-65. Crossref

Ames, E. P., and J. Lichter.

2013. Gadids and alewives: structure within complexity in the Gulf of Maine. Fish. Res. 141:70-78. Crossref

Azarovitz, T. R.

1981. A brief historical review of the Woods Hole Laboratory trawl survey time series. In Bottom trawl surveys (W. G. Doubleday and D. Rivard, eds.), p. 62-67. Can. Spec. Publ. Fish. Aquat. Sci. 58. [Available from website.]

Bhattacharyya, A.

1943. On a measure of divergence between two statistical populations defined by their probability distribution. Bull. Calcutta Math. Soc. 35:99-109.

Cadrin, S. X., G. R. DeCelles, and D. Reid.

2016. Informing fishery assessment and management with field observations of selectivity and efficiency. Fish. Res. 184:9-17. Crossref

Chang, S., W. W. Morse, and P. L. Berrien.

1999. Essential fish habitat source document: white hake, Urophycis tenuis, life history and habitat characteristics. NOAA Tech. Memo. NMFS-NE-136, 23 p. [Available from website.]

Cochran, W. G.

1977. Sampling techniques, 3rd ed., 448 p. John Wiley and Sons, New York.

Engås, A., S. Løkkeborg, A. V. Soldal, and E. Ona.

1996. Comparative fishing trials for cod and haddock using commercial trawl and longline at two different stock levels. J. Northwest Atl. Fish. Sci. 19:83-90. Crossref

Fahay, M. P., P. L. Berrien, D. L. Johnson, and W. W. Morse. 1999. Essential fish habitat source document: Atlantic cod, Gadus morhua, life history and habitat characteristics. NOAA Tech. Memo. NMFS-NE-124, 41 p. [Available from website.]

Hilborn, R., and C. J. Walters.

1992. Quantitative fisheries stock assessment: choice, dynamics and uncertainty, 570 p. Chapman and Hall, New York.
Holt, R. D.

1987. Population dynamics and evolutionary processes: the manifold roles of habitat selection. Evol. Ecol. 1:331-347. Crossref

Hutchings, J. A., and J. D. Reynolds.

2004. Marine fish population collapses: consequences for recovery and extinction risk. BioScience 54:297-309. Crossref

Lawton, J. H.

1993. Range, population abundance and conservation. Trends Ecol. Evol. 8:409-413. Crossref

Macdonald, J. S., M. J. Dadswell, R. G. Appy, G. D. Melvin, and

D. A. Methven.

1984. Fishes, fish assemblages, and their seasonal movements in the lower Bay of Fundy and Passamaquoddy Bay, Canada. Fish. Bull. 82:121-139.

Maunder, M. N., P. R. Crone, J. L. Valero, and B. X. Semmens.

2014. Selectivity: theory, estimation, and application in fishery stock assessment models. Fish. Res. 158:1-4. Crossref

McElroy, W. D., L. O’Brien, J. Blaylock, M. H. Martin, P. J. Rago,

J. J. Hoey, and V. A. Sheremet.

2019. Design, implementation, and results of a cooperative research Gulf of Maine longline survey, 2014-2017. NOAA Tech. Memo. NMFS-NE-249, 68 p. [Available from website.]

Millar, R. B., and R. J. Fryer.

1999. Estimating the size-selection curves of towed gears, traps, nets and hooks. Rev. Fish Biol. Fish. 9:89-116. Crossref

NEFSC (Northeast Fisheries Science Center).

2008. Assessment of 19 Northeast groundfish stocks through 2007: report of the 3rd groundfish assessment review meeting (GARM III), Northeast Fisheries Science Center, Woods Hole, Massachusetts, August 4-8, 2008. Northeast Fish. Sci. Cent. Ref. Doc. 08-15, 884 p. [Available from website.]

2013a. 55th Northeast regional stock assessment workshop (55th SAW) assessment report. Northeast Fish. Sci. Cent. Ref. Doc. 13-11, 845 p. [Available from website.]

2013b. 56th Northeast regional stock assessment workshop (56th SAW) assessment report. Northeast Fish. Sci. Cent. Ref. Doc. 13-10, 868 p. [Available from website.]

2017. Operational assessment of 19 Northeast groundfish stocks, updated through 2016. Northeast Fish. Sci. Cent. Ref. Doc. 17-17, 259 p. [Available from website.]

Nye, J. A., J. S. Link, J. A. Hare, and W. J. Overholtz.

2009. Changing spatial distribution of fish stocks in relation to climate and population size on the Northeast United States continental shelf. Mar. Ecol. Prog. Ser. 393:111-129. Crossref

Orio, A., U. Bergström, A.-B. Florin, A. Lehmann, I. Šics, and M. Casini.

2019. Spatial contraction of demersal fish populations in a large marine ecosystem. J. Biogeogr. 46:633-645. Crossref

Riley, S. J., S. D. DeGloria, and R. Elliot.

1999. A terrain ruggedness index that quantifies topographic heterogeneity. Intermt. J. Sci. 5:23-27.

Sampson, D. B., and R. D. Scott.

2012. An exploration of the shapes and stability of populationselection curves. Fish Fish. 13:89-104. Crossref

Scharf, F. S., F. Juanes, and R. A. Rountree.

2000. Predator size-prey size relationships of marine fish predators: interspecific variation and effects of ontogeny and body size on trophic-niche breadth. Mar. Ecol. Prog. Ser. 208:229-248. Crossref

Scott, J. S

1982. Selection of bottom type by groundfishes of the Scotian Shelf. Can. J. Fish. Aquat. Sci. 39:943-947. Crossref 
Stauffer, G.

2004. NOAA protocols for groundfish bottom trawl surveys of the nation's fishery resources. NOAA Tech. Memo. NMFS-F/SPO-65, 205 p. [Available from website.]

Swain, D. P., and E. J. Wade.

1993. Density-dependent geographic distribution of Atlantic cod (Gadus morhua) in the southern Gulf of St. Lawrence. Can. J. Fish. Aquat. Sci. 50:725-733. Crossref

Tamdrari, H., M. Castonguay, J.-C. Brêthes, and D. Duplisea.

2010. Density-independent and -dependent habitat selection of Atlantic cod (Gadus morhua) based on geostatistical aggregation curves in the northern Gulf of St. Lawrence. ICES J. Mar. Sci. 67:1676-1686. Crossref

Wieland, K., E. M. F. Pedersen, H. J. Olesen, and J. E. Beyer. 2009. Effect of bottom type on catch rates of North Sea cod (Gadus morhua) in surveys with commercial fishing vessels. Fish. Res. 96:244-251. Crossref

Winner, K., M. J. Noonan, C. H. Fleming, K. A. Olson, T. Mueller, D. Sheldon, and J. M. Calabrese.

2018. Statistical inference for home range overlap. Methods Ecol. Evol. 9:1679-1691. Crossref 